agement of the apparatus free from difficulties and complications. It is destined to do much for urinary surgery, as well as for other fields requiring constant drainage. ${ }^{29}$

\section{THE SUPERNUMERARY URETER}

\section{REPORT OF A CASE OF COMPLETE UNILATERAL DUPLICATION}

\section{A. R. SIMON, M.D. AND \\ H. O. MERTZ, M.D.} LAPORTE, IND.

Reports of supernumerary ureters are becoming more frequent, which very frequency demands records of all such cases, as it emphasizes the possibility of the existence of such an anomaly in every obscure condition of the upper urinary tract. While congenital change in a ureter may be associated with corresponding variation in the kidney, the ureteral condition, whether it be an alteration in form, ${ }^{1}$ in location, ${ }^{2}$ or in number, ${ }^{3}$ will not infrequently be the principal factor in the production of a pathologic condition.

\section{REPORT OF CASE}

History.-Mrs. J. W., Polish, aged 26 , with negative previous history, during the forenoon of April 15, 1914, experienced a sudden severe pain in the upper right abdomen, relieved somewhat by pressure, with no tendency to radiation and not associated with nausea or vomiting. The urine contained macroscopic blood, and a moving renal calculus was suspected; further diagnostic measures at this time, however, were refused. The patient was again seen, Aug. 7. 1915, when she came complaining of a marked dysuria with a constant throbbing pain over the bladder region. She was having frequent bladder spasms, at which time a few drops of bloody urine would be expelled. While the severe abdominal pain had not been repeated, during the past sixteen months she had had periods of bladder irritability. Her present attack began four months before, and gradually grew worse, until when seen she was having no rest night or day. She had missed the last two menstrual periods.

Physical Examination.-Palpation elicited tenderness over the bladder region, and vaginal examination, with pressure on the trigon of the bladder, was extremely painful. The terminal portion of the right ureter as palpated by the vagina was prominent and sore. There was a dull ache over the right kidney posteriorly, and deep fist percussion over this

29. In addition to the references already given, the following will be found of interest:

Hamilton, A.: An Apparatus for the Intermittent Postoperative Drainage of the Bladder, THE Journal A. M. A., 1908, 1, 962.

Connel, K.: A Suction Apparatus for Continuous Drainage, Ann. Surg., 1903, xxxvii, 886.

Wacobarn: Rev. méd., Jan. 1, 1899; abstr., The Journal A. M. A., 1899, xxxii, 432 .

Walker, J. B.: Continuous Drainage of Bladder, Ann. Surg., 1899, Xxx, 515.

Churchman, J. W.: The Use of Suction in the Postoperative Treatment of Bladder Cases, Bull. Johns Hopkins Hosp., 1916, xxvii, 69.

1. Eisendrath, D. N.: Ann. Surg., 1912, 1v, 571 .

1. Eisendrath, D. N.: Ann. Surg., 1912,

3. Lewis: Med. Rec., New York, Oct. 6, 1906, p. 521. area produced pain. The temperature was 99.2, the pulse 100 . The blood Wassermann was negative.

Catheterized bladder urine, $1 \frac{1 / 2}{2}$ ounces, contained 0.25 per cent. albumin, from five to ten pus cells and from ten to twelve blood cells to the $1 / 8$ objective, with few short strings of streptococci. The last few drops of urine, as they flowed from the catheter, were red with fresh blood. Catheterization was painful.

Cystoscopic Examination.-Cystoscopy was performed, Aug. 14, 1915, and demonstrated a violently inflamed trigon with flakes of pus and mucus clinging to its raw surface. Just to the right of the median line, situated on the posterior margin of the trigon, was a small papilloma. Later twice applying the high frequency spark caused it to disappear entirely. The left ureteral meatus was normal in contour, but located at an abnormally high position in the bladder. On the right side of the bladder at its usual location was the right ureteral orifice, edematous and congested, while downward and inward from this meatus, in the substance of the trigon, was a third opening, almost round, larger than the normal and devoid of the normal liplike folds. The inflammatory process centered about this opening. There were two small ulcerations located as indicated in Figure 1 . The remainder of the bladder was normal.

Urine was observed coming from the left and upper right openings in a normal manner, while from the lower right opening it could be detected only at long intervals and then not with normal force. At a later examination, Sept. 5, 1915, the opening was found entirely covered with mucus. It was watched for several minutes, but no urine was seen passing from this opening; but when with the tip of a ureteral catheter the mucus was removed, a larger quantity than had at any time previously been observed coming from it passed into the bladder. During ureteral micturition this opening did not advance into the cystoscopic field as does the normal, and it remained open when passive. The relative sizes of the three openings are accurately recorded in Figure 1.

Urine from the left kidney contained 2.6 per cent. urea. Phenolsulphonephthalein appeared from this kidney in three minutes, assuming a deep color in four minutes. Urine collected from the upper right opening contained an occasional short string of streptococci. Urea was 2.5 per cent. and phenolsulphonephthalein appeared in four minutes, assuming a deep color in seven minutes. Urine collected from the lower right opening showed an occasional pus cell, many strings of streptococci, urea only 0.3 per cent., and phenolsulphonephthalein appeared in fifteen minutes in traces only. The quantity of urine secreted was only one-third that collected through each of the other two catheters in the same length of time. Examinations for tubercle bacilli were negative.

Thorium nitrate was injected, and pyelograms were made of the right kidney (Fig. 2). Both kidneys were well up in place. The two pelves of the right kidney were completely separated, and the ureter from the rudimentary cephalic pelvis entered the bladder at the caudal opening. This ureter was the larger. The exact relative position of the two ureters in their course varied, as determined by roentgenograms taken at few minute intervals, the ureter from the lowermost pelvis being more mobile. Just before the ureters entered the bladder they crossed, the ureter leading to the lower- 
most, supernumerary bladder opening passing posteriorly, a relation constant in all our roentgenograms.

In this review of our case, we wish to emphasize: (1) The frequency of the supernumerary ureter, (2) the surgical significance the anomaly may assume, and (3) the possibility of its recognition as a factor in the production of a pathologic condition early in the process.

\section{THE FREQUENCY OF URETERAL DUPLICATION}

Complete bilateral duplication of the ureters is rare. Levison, ${ }^{-1}$ in reviewing the subject in 1907, found only nine cases. Braasch has observed only one case. The condition has been reported by Huntington, ${ }^{6}$ Pawlow, ${ }^{7}$ Wertheim, ${ }^{8}$ Lydston, ${ }^{9}$ Rumpel, ${ }^{10}$ Kelly, ${ }^{11}$ and others. A complete study of the anomaly was made by Brown, Englebach and Carmen ${ }^{12}$ in reporting their case.

Complete unilateral duplication is more frequent. Motzfeldt ${ }^{13}$ found twenty-three double ureters in 4,500 necropsies. Huntington, ${ }^{14}$ in 5,000 dissections, is reported as having found only five cases of ureteral doubling. Wertheim, ${ }^{8}$ in 500 operations for carcinoma of the uterus, records only six cases of complete unilateral duplication. In the clinical case demanding urologic investigation, the frequency is more marked. Pawlow ${ }^{7}$ observed three cases and reports six others. Braasch, in 1912, reported seven cases of unilateral complete division of the ureter, and Weigert ${ }^{15}$ saw seven cases in one year.

Huntington concludes from his dissections that the most common ureteral anomaly is a double pelvis and ureter, with the ureters uniting before entering the bladder. Cases of single pelvis with the ureter dividing above its insertion into the bladder have been reported. Ransohoff ${ }^{16}$ states that a duplication of half of a ureter is present in 1 per cent. of all subjects.

4. Levison, referred to by White and Martin: Genito-Urinary and Venereal Diseases, Ed. 8, p. 506

5. Braasch: Ann. Surg. 1912, lvi, 727

6. Huntington: Harvey Lectures, Series II, 1906-1907, Philadelphia

J. B. Lippincott Co., 1908.

7. Pawlow: Deutsch Ztschr. f. Chir., 1913, cxxi, 425

8. Wertheim, quoted by Brown: Am. Jour. Obst., 1915, 1xxi, 669.

9. Lydston: A Text-Book on Genito-Urinary, Venereal and Sexual Diseases, Philadelphia, F. A. Davis Co. 1900, p. 843 .

10. Rumpel: Cystoscopy as Adjuvant in Surgery, New York, Rebman
10. Rut 10. Rumpel: 7 .

I1. Kelly and Burnam: Diseases of the Kidneys, Ureters and Bladder, New York, D. Appleton \& Co., 1914, ii, 329.

12. Brown, Englebach and Carmen: Tr. South. Surg. and Gynec, Assn., 1909, xxii, 248 .

13. Motzfeldt: Norsk Mag. f. Lægevidensk., July, 1914.

13. Motzfeldt: Norsk Mag. f. Lægevidensk., July, 1914.
14. Huntington, quoted by Furniss: Am. Jour. Obst., 1915, 1xxi, 669 14. Huntington, quoted by Furniss: Am. Jour. Obst., 1915, 1xxi, 669 . 15. Weigert, quoted by von Bergman and Bull: System of Practical
Surgery, Philadelphia, Lea Bros. \& Co., 1904, v, 225.

16. Ransohoff: Keen's Surgery, Philadelphia, W. B. Saunders, 1909, iv, 203 .

\section{THE SURGICAL SIGNIFICANCE OF THE SUPER-} NUMERARY URETER

Not infrequently ureteral anomalies, the surgical significance of which depends on the predisposition their very presence exerts on the development of hydronephrosis and infection, are associated with prenatal renal formations ${ }^{17}$ which persist throughout life, rendering resistance to such changes below normal. The possibility of the existence of this congenital alteration of the kidney lends an added clinical importance to every case of supernumerary ureter. The surgical interest in a supernumerary ureter, however, is very much governed by the location of its meatus. Should the opening be extravesical, its correction is possible only by surgical intervention. When intravesical, its relative position in the bladder will influence its surgical importance. When located in the trigon near the vesical neck, the folds of the mucous membrane act as valves, closing the opening and resulting in hydronephrosis. ${ }^{10}$ Should it be near the normal site of the ureteral meatus, this difficulty is not encountered; but if the opening be abnormally small, a condition which usually prevails, stasis is inevitable and infection is prone to occur. If the opening is of normal size and has its normal sphincterlike action, the condition can remain latent throughout life, and if discovered will be of no clinical interest; but when there are no liplike folds about the opening, and it remains open when passive, although of normal size, the condition becomes a potential one for harm. Draper and Braasch $^{18}$ assert that this "mechanical action of the valve can be dispensed with" if the "glomerulotubular pressure is maintained at normal."

In our case there was an absence of the sphincterlike action; the meatus did not grasp the introduced catheter as does the normal meatus; the orifice remained open at all times; it was the largest of the three meatuses, and we considered that the glomerulotubular pressure was lessened, as we felt justified in believing that merely sealing the meatus by mucus was sufficient to obstruct the flow of urine completely. The physiologic action ${ }^{19}$ of the meatus being absent, and the force of the urinary efflux into the

17. Losee: Am. Jour. Obst., 1915, 1xxi, 672.

18. Draper, J. W., and Braasch, W. F.: The Function of the Ureterovesical Valve, The Journal A. M. A., Jan. 4, 1913, p. 20.

19. Kretschmer and Greer: Sur A Pasteau O. A. M. Role of the Lymphatics in Ascending Renal Infection, THE Journat A. M. A., Feb. 19,1916 , p. 561 . 
bladder being below normal, conditions were ideal for regurgitation and infection from below, should such be possible.

As indicated, there was a wide variation in the character of the urine from the two ureters of the right kidney.

Certain writers ${ }^{7}$ have suggested the possibility of the development of a constriction of one ureter at the point at which the two ureters cross, thus producing stasis, it usually being the ureter draining the cephalic pelvis most affected. In our case, because of the ireely movable condition of the one ureter, such a complication would seem improbable.

In a partial duplication of a ureter, the narrowing of the canal at its point of division, and the change in its projection thus produced, will often lend the condition a surgical importance.

THE DETECTION OF THE SLPERNUMERARY URETER PRODUCING SYMPTOMS

The clinical history of a constant incontinence associated with periods of normal urination at once suggests the existence of a supernumerary ureter with an extravesical opening. It may be extremely difficult to locate the orifice of a supernumerary aberrant ureter. Furniss ${ }^{20}$ and Kelly ${ }^{11}$ have exhaustively reviewed the various locations of these meatuses and the difficulties encountered in their detection. When the opening is intravesical, this symptom does not obtain, and the determination that an existing renal stasis or infection is associated with a ureteral anomaly, by the symptomatology alone, is impossible.

Many such anomalies will at once be recognized by cystoscopy, and there is always some irregularity in the bladder picture. But should the opening of the third ureter be among the folds of the trigon or vesical neck, chromo-ureteroscopy may be necessary. Mucus covering the opening, as in our case, may prove confusing, and add to the difficulties in a diagnosis. Should a ureteral division exist above its vesical opening, the anomaly cannot be diagnosed by cystoscopy alone. Pawlow records a case of complete duplication of the ureter until the bladder wall was reached when the two ureters joined, having a common bladder opening. It is by the combined use of the cystoscope and Roentgen ray that such cases may be detected. In every cystoscopically diagnosable ureteral anomaly, the course of the ureters should be determined, by means of the roentgenogram with leaded ureteral catheters inserted; but in cases such as Pawlow $^{7}$ and Young $^{21}$ report, this may be insufficient and misleading, when pyelography will be necessary. Any anatomic or physiologic alteration in the pelvis can thus be determined also. That the case of partial ureteral duplication may be identified, the ureteral catheter should be introduced just within the meatus, and the thorium allowed to flow into the ureter. Findings at dissection would indicate that many cases of partial duplication are being overlooked by the clinician. The Roentgen ray alone, because of the enlarged kidney shadow, may suggest the anomaly, yet an accurate diagnosis cannot thus be made. ${ }^{22}$ The functional and bacteriologic tests, possible with the separate collection of urine through the catheter, have the same diagnostic value as in other urologic cases.

20. Furniss: Surg., Gynec. and Obst., 1914, xviii, 584.

21. Young, quoted by Kelly and Burnam (Footnote 11).

22. Brown: Boston Med. and Surg. Jour., 1914, clxxi, 373.
It is most often the ureter draining he cephalic pelvis which has the abnormally placed opening, which is usually lower and nearer the midline, conforming to Weigert's rule. Braasch ${ }^{5}$ reports by illustration two cases with the ureter draining the cephalic pelvis entering the bladder at the cephalic vesical orifice.

With the examination of a case as thus outlined, it is possible to recognize clinically every case of ureteral anomaly, and determine its surgical importance before a terminal pathology is encountered.

With all available data in our case, any explanation of the attack of abdominal pain in 1914 must be purely speculative. We had a complete duplication of the right ureter, with separation of the two pelves, the cephalic one being rudimentary. There was evidence of infection of this supernumerary pelvis, and the function of this portion of the kidney was poor. With the progress of pregnancy, postural treatments and the employment of urinary antiseptics, the bladder symptoms disappeared. The dull ache remained over the right lumbar region, and cystoscopy demonstrated, Dec. 20, 1915, the third opening still inflamed, with an existing edema of the subjacent mucosa. The remainder of the bladder was normal.

There was no special diagnostic significance in the presence of the papilloma.

\section{CONCLUSIONS}

1. Supernumerary ureters are more common than generally appreciated by the clinician.

2. They may be productive of a pathologic condition demanding surgical correction.

3. An otherwise benign condition may be rendered malignant through the association with a supernumerary ureter.

4. Their recognition is possible in every case.

5. In our case, the unilateral duplication had a direct bearing on the progress of the pathologic process.

\section{THE 'TREATMENT OF GONORRHEȦL FOL- LICULITIS BY CAUTERIZATION WITH THE D'ARSONVAL CURRENT}

EDGAR G. BALLENGER, M.D.

Fellow of the American College of Surgeons AND

OMAR F. ELDER, M.D. ATLANTA, GA.

In July, 1915, Swinburne ${ }^{1}$ directed attention to fulguration in the treatment of gonorrheal folliculitis. Since October, 1915, we have employed the method suggested by him and clesire to record the unusually satisfactory results obtained by this treatment in recurrent and chronic gonorrhea.

For many years we have understood the part played by the glands of Littre and the crypts of Morgagni in harboring the gonococci where medication could not reach them. Knowing this, however, heretofore has been of small importance because there was no definite, dependable remedy to eradicate the organisms or destroy their foci. To Swinburne belongs the credit for evolving a method for the destruction of these protected recesses. This can be readily and certainly done by inserting an electrode into the follicle

1. Swinburne: Med. Rec., Nery York, July 31, 1915. 